\title{
Comportamento preferido de liderança e sua influência no desempenho dos atletas
}

\author{
M.R.F. Brandão, D. Carchan
}

O objetivo desse estudo foi avaliar a percepção que atletas de voleibol têm sobre o comportamento de seu treinador e sua relação com a atuação em jogos. Para tanto, foram avaliados 12 jogadores de uma equipe masculina de voleibol de alto rendimento brasileira, com média de idade de 20.6 anos, através de uma única questão geradora. As respostas foram analisadas através do Discurso do Sujeito Coletivo. Os resultados mostram que $75 \%$ dos atletas tendem a perceber o comportamento do treinador e sua influência na atuação de uma forma direta ("A liderança do técnico é essencial na minha atuação"); $17 \%$ de uma forma subordinada ("Às vezes sim, às vezes não, depende...") e $8 \%$ de não influência ("Liderança e atuação são coisas distintas"). Concluindo, pode-se dizer que há uma tendência dos jogadores perceberem que a forma como o treinador exerce sua liderança pode influenciar diretamente em sua atuação no jogo.

Palavras-chave: voleibol, treinador, discurso sujeito coletivo

\section{Leadership preferences behaviors and its influence on athletes' performance}

The main objective of this study was to evaluate volleyball athletes' perception of the coach behavior and its relationship with the performance in games. For those, 12 male, Brazilian volleyball high-level players, with mean of age 20.6 years were evaluated through an open question: "Do you see a relationship between the leadership style of your coach and your performance in games? The answers were analyzed through the Discourse of the Collective Subject. Data showed that $75 \%$ of the players tended to perceived the coach behavior as influencing directly their performance ("The coach leadership is essential for my performance"); $17 \%$ perceive it in a subordinate way ("Sometimes yes, sometimes, no, depends..."), and $8 \%$ perceived as no influence ("Leadership and performance are different"). In conclusion we can say that there is a tendency to perceive the coach behavior as directly connected with the performance.

Keywords: volleyball, coach, discourse of the collective subject 
Muito se tem feito para que os atletas apresentem um rendimento ótimo, mas, a participação em uma competição desportiva de alto nível pode ter vários efeitos psicológicos para o atleta, como por exemplo, ansiedade, medo, stress e, o estilo de liderança do treinador de uma equipe é, sem dúvida, um fator de suma importância. Na opinião de Buceta (2009) o treinador é o responsável máximo pelo funcionamento dos aspectos associados à equipe assim como com o rendimento de seus atletas, razão pela qual as suas decisões e ações têm uma grande influência. Dos acertos e erros do treinador dependem em grande medida o êxito esportivo e a satisfação dos que trabalham sobre seu mando.

Há algumas décadas, psicólogos do esporte e pesquisadores vêm tentando entender as questões referentes à liderança (Chelladurai, 1993; Chelladurai, Haggerty, \& Baxter, 1989; Côté Salmela, Trudel, Baria, \& Russell, 1995; Horn, 1992; Serpa, 1996, 1997; Weinberg \& Gould, 2001). Porém, a liderança é um dos tópicos da Psicologia do Esporte que necessita de mais estudos nas diferentes modalidades e contextos esportivos (Chelladurai \& Saleh, 1980).

Para pesquisarmos o processo de liderança e os líderes esportivos, parece lógico que devemos primeiro, entender o que é liderança e como ela se manifesta em vários ambientes. O conceito de liderança é um tópico muito amplo e, por esse motivo, possui inúmeras definições. Segundo Brandão e Valdés (2005) em uma revisão acerca do termo liderança existe um consenso de que liderança significa a capacidade de influenciar pessoas para trabalharem juntas, para o alcance das metas e objetivos, de maneira harmônica.

Os líderes, normalmente, são escolhidos por alguém, mas, eles também podem surgir espontaneamente no grupo, sendo que esses são mais efetivos porque possuem o respeito e o apoio de membros da equipe ou do grupo. Geralmente, os líderes que surgir espontaneamente no grupo possuem habilidades de liderança especiais ou grande capacidade no esporte.

$\mathrm{Na}$ década de 20, pesquisadores tentaram determinar quais características ou traços de personalidade eram comuns a grandes líderes em diferentes ambientes. Tais pesquisadores eram favoráveis à teoria de traço, ou seja, acreditavam que traços de liderança eram características de personalidade relativamente estáveis, da mesma forma que inteligência, otimismo, independência e autoconfiança. Portanto, para eles os líderes bem sucedidos possuíam certas características de personalidade que os tornariam prováveis de serem líderes, independentemente da situação que se encontrassem (Weinberg \& Gould, 2001).

Historicamente, para estudar a liderança no esporte, os pesquisadores utilizaram escalas designadas para $\mathrm{O}$ segmento industrial e militar a fim de explicar o comportamento do líder, e a preferência do comportamento do líder pelos colegas de trabalho. Porém, alguns pesquisadores, mostraram que essas escalas nas situações esportivas, em geral, são inaplicáveis, pelo simples fato de não serem apropriadas para tais ambientes (Terry \& Howe, 1984). A 
investigação com base nas teorias da personalidade tendiam a definir a liderança como um traço desta. Porém, a abordagem de traço perdeu credibilidade quando Stogdill (1974) revisou mais de uma centena de estudos de liderança sob a perspectiva da teoria do traço e encontrou que poucos traços de personalidade eram consistentes, ou seja, embora alguns pareçam ser úteis para um líder, eles certamente não são fundamentais, nem garantem uma liderança bem-sucedida. Em função dos resultados de Stogdill, os pesquisadores buscaram encontrar comportamentos universais de líderes efetivos (Weinberg \& Gould, 2001). Assim, os comportamentalistas argumentaram que qualquer um poderia ser ensinado a se tornar um líder, simplesmente, aprendendo os comportamentos de outros líderes efetivos.

Pesquisadores da Universidade de Ohio utilizaram o questionário de Descrição de Comportamento de Liderança para descrever como líderes se comportavam em organizações comerciais, militares, educacionais e governamentais. Verificaram que, a maior parte do que os líderes fazem se enquadra em duas categorias: consideração e estrutura inicial. Consideração refere-se à amizade, confiança mútua, respeito e afetividade entre o líder e os subordinados e, estrutura inicial a comportamentos como estabelecer regras e regulamentos, canais de comunicação, métodos de procedimento e padrões bem-definidos de organização para atingir metas e objetivos. Portanto, verificaram que líderes bem sucedidos tendem a ter valores altos tanto em consideração quanto em estrutura inicial.

No esporte e no exercício a definição de liderança engloba várias dimensões do comportamento do treinador, como, por exemplo, seu processo de tomada de decisão, o tipo e a frequência com que fornece o estímulo aos seus atletas, seu desempenho, as técnicas de motivação utilizadas e a forma de relação que estabelece com seus atletas (Buceta, 2009; Horn, 1992). Foram elaborados, então, questionários específicos para o esporte e, em 1976, uma metodologia interessante foi criada por Tharp e Gallimore (cit. por Weinberg \& Gould, 2001). Trata-se de um relatório de registro no qual o pesquisador listava vários comportamentos típicos de técnicos e a frequência com que esses comportamentos aconteciam. Geralmente, mais de um avaliador registrava os comportamentos, a fim de melhorar a confiabilidade do estudo. Através desse relatório, o pesquisador registrava o tempo gasto pelo técnico com instruções verbais, com correção, com elogios e com declarações de desagrado.

Chelladurai e Saleh (1980) desenvolveram um modelo específico para a mensuração do comportamento de liderança no esporte, denominado Modelo Multidimensional de Liderança no Esporte. Dentre outros aspectos, o modelo enfatiza a importância do comportamento atual do treinador e se esse corresponde ao comportamento preferido pelos atletas. A proposta do modelo é verificar se a satisfação do atleta coincide diretamente com o comportamento do treinador, e também, relatar 
se o comportamento atual do treinador corresponde a efeitos positivos no desempenho do atleta.

Nesse modelo, a liderança é vista como um processo interacional, ou seja, a efetividade do líder no esporte depende de características circunstan- ciais tanto do líder como dos membros do grupo (Cruz \& Gomes, 1996). Portanto, a liderança efetiva pode variar dependendo das características dos atletas e das limitações e exigências impostas pela situação ou meio esportivo (figura 1).

\section{ANTECEDENTES COMPORTAMENTOS DO LÍDER CONSEQUENCIAS}

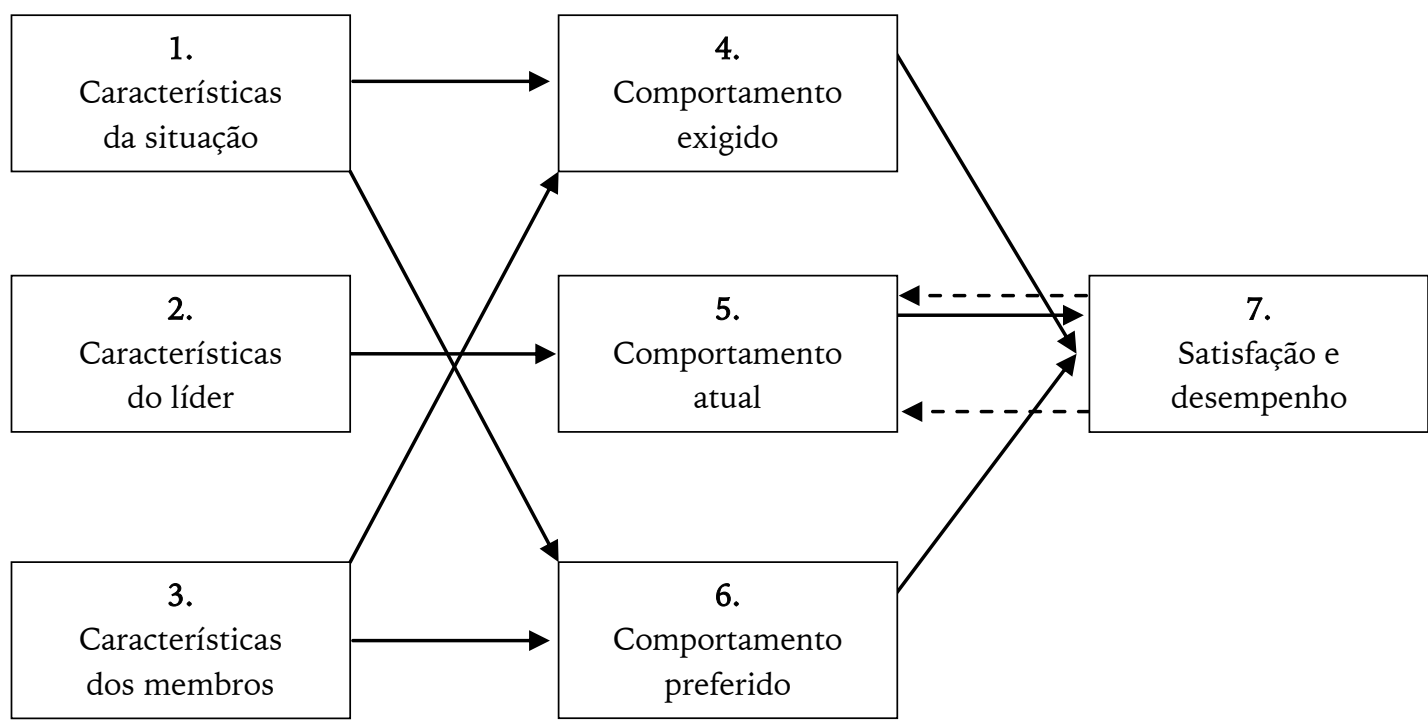

Figura 1. Modelo multidimensional de liderança para esportes (adaptado de Chelladurai, 1993)

Pode-se observar na figura 1 que o rendimento do grupo e a satisfação dos atletas (caixa 7 na figura) dependem de três tipos de comportamento do líder: comportamentos exigidos (caixa 4), preferidos (caixa 6) e atuais (caixa 5). A situação (caixa 1), o líder (caixa 2) e os membros (caixa 3) levam a três tipos de comportamento, por isso são chamados de antecedentes. As características do líder são o fator pessoal, enquanto as características situacionais e as características dos membros são os fatores circunstanciais. Um resultado positivo - ou seja, ótimo desempenho e satisfação do grupo - acontecerão se os três aspectos do comportamento do líder estiverem de acordo. Se o líder se comportar adequadamente para a situação em particular, ou seja, se os comportamentos exigidos, os comportamentos preferidos e os comportamentos atuais do treinador forem consistentes e congruentes, e esses comportamentos se ajustarem às preferências dos membros do grupo, eles atingirão seu melhor desempenho e se sentirão satisfeitos. No modelo multidimensional de liderança no esporte, o treinador pode apresentar três tipos de comportamento. São eles: a) Comportamento exigido ou requerido do líder: Cada situação exige ou impõe um comportamento diferente do líder. Como por 
exemplo: a estrutura organizacional, as normas e os valores do clube ou do grupo ditam um comportamento. Em outras palavras, as normas são estabelecidas pela organização e espera-se que as pessoas se ajustem às normas estabelecidas; b) Comportamento preferido do líder: Os membros do grupo têm preferências por determinados tipos de comportamentos do líder. Essas preferências são dependentes não só de variáveis como a idade, o sexo e o tempo de experiência no esporte, mas também de variáveis de personalidade (como a necessidade de realização, de afiliação e de competência na tarefa) influenciam a preferência por um determinado membro; c) Comportamento atual ou real do líder: Comportamentos atuais do líder são os comportamentos que o líder exibe, tais como ser capaz de estruturar ou ser atento. Características do líder, como personalidade, capacidade e experiência (caixa 2 na figura 1), afetam esses comportamentos diretamente. Acredita-se que o comportamento atual é indiretamente afetado tanto pelas preferências do grupo como pelas exigências da situação.

Exatamente por se tratar de um modelo no qual a liderança é entendida como um processo de interação leva em consideração não só as características situacionais e as características do líder, mas também as dos membros do grupo (Lopes, Samulski, \& Noce, 2004). Outro modelo interessante para o estudo da liderança é o Modelo de Comportamentos Ansiogênicos do Treinador (Serpa, 1997) - ver figura 2.

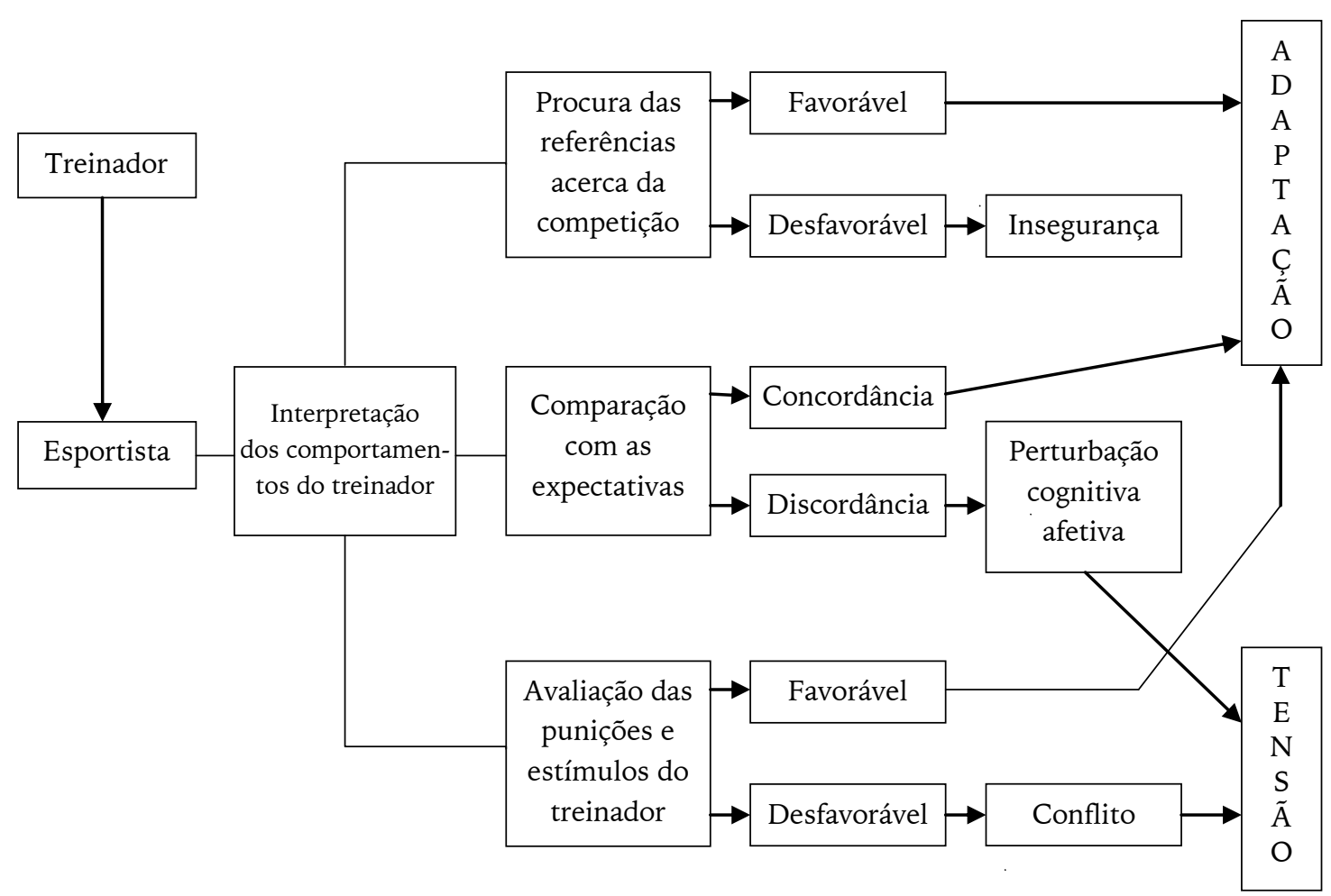

Figura 2. Modelo de comportamentos ansiogênicos do treinador (adaptado de Serpa, 1997) 
O modelo de comportamentos ansiogênicos do treinador demonstra $o$ modelo das interpretações dos atletas sobre o comportamento dos treinadores. Pode-se observar que, segundo esse modelo, o atleta busca referência na conduta do líder sobre sua competência, compara a conduta que observa no líder com as suas expectativas e avalia os castigos e os prêmios que seu líder aplica. Em cada um desses casos se estabelecem conclusões que podem levar a variados sentimentos: insegurança, distúrbios cognitivos e emocionais, que por sua vez podem gerar tensão. Esses sentimentos podem também, não aparecer e aí, então, ocorrerá um processo de adaptação.

Pesquisa realizada em 1995 avaliou comportamentos de 17 técnicos de ginástica artística usando uma abordagem de entrevista qualitativa para saber como usavam seu conhecimento durante os treinamentos (Côté et al., 1995). Os comportamentos exibidos com mais frequência foram: fornecer um ambiente de apoio por meio de "feedback" positivo; dar instrução técnica com relação aos progressos, ensinar habilidades mentais; dar oportunidades que simulam as demandas mentais e técnicas da competição; fornecer treinamento para garantir a segurança e, enfatizar o condicionamento para assegurar a prontidão física do ginasta.

Os estudos revelaram de forma consistente que o "feedback" de apoio positivo e o "feedback" técnico corretivo ajudaram os atletas a melhorar seu desempenho. Portanto, a chave para a liderança esportiva efetiva seria focalizar-se no positivo, fornecendo com clareza "feedback" e instruções técnicas:

[...] "Um líder sabe para onde o grupo ou a equipe está indo (suas metase objetivos) e fornece a direção e os recursos para chegar lá. Técnicos que são bons líderes fornecem não apenas uma visão daquilo pelo que se luta, mas também a estrutura, a motivação e o apoio do diaa-dia para transformar a visão em realidade" (Weinberg \& Gould, 2001, p. 212).

No âmbito esportivo, os líderes trabalham por meio de relacionamentos interpessoais e oferecem orientação, metas e estrutura para suas equipes. Não se sabe o quanto o comportamento de liderança do treinador interfere na derrota ou na vitória de uma partida, mas não restam dúvidas de que ele exerce um papel importante na busca do rendimento de uma equipe, e como líder é o principal responsável (Buceta, 2009; Simões, 1994).

Muitas pessoas crêem que a principal tarefa de um treinador se resume em melhorar as habilidades físicas, técnicas e táticas de seus esportistas. É evidente que essas tarefas são essenciais para o alcance da excelência da prática esportiva e são responsabilidades do treinador, porém, os treinadores também são cruciais no trabalho de guiar os seus esportistas em seu desempenho de forma consistente, apesar do esgotamento, da pressão, dos oponentes e das diferentes circunstâncias esportivas da competição (Brandão \& Valdés, 2005).

Para que o líder esportivo consiga com que os membros de uma equipe desempenhem, com o máximo esforço, a busca de seus objetivos é fundamen- 
tal que ele possua certas características de personalidade listadas a seguir (Brandão \& Valdés, 2005): entusiasmo: treinadores com alto grau de entusiasmo tendem a influenciar positivamente seus esportistas; integridade: os esportistas necessitam confiar que seu líder está comprometido com o trabalho que desenvolve, é honesto e fala sempre a verdade; sentido de propósito e direção: um bom líder de grupo precisa ter domínio do treinamento e conhecimento da modalidade que trabalha; disposição: para poder suportar a demanda física e psíquica o treinador precisa ter muita disposição e uma alta capacidade para trabalhar com as cargas requeridas; coragem: um treinador necessita ter determinação para tomar decisões e selecionar, entre várias possibilidades, as ações mais adequadas para o momento.

Sobre as múltiplas funções de um treinador a multidimensionalidade de seu papel foi assinalada por um número relevante de autores ao longo das últimas décadas (Brandão \& Valdés, 2005; Buceta, 2009; Cruz \& Gomes, 1996). O técnico esportivo é o responsável por promover a produção e regular as relações afetivas, além de ser intitulado o confidente e fonte de referências essenciais de seus atletas. Somado a isso, o treinador, precisa também ser capaz de respeitar e seguir as regras e os objetivos de um contexto organizacional, e ainda respeitar as características individuais dos membros do grupo e da organização, sendo a sua conduta, reflexo das suas próprias características (Serpa, 1997; Simões, 1994).
Estudos realizados com treinadores de equipes de alto rendimento esportivo observaram que os treinadores demonstraram uma alta tensão em função de diferentes fatores: o desgaste da profissão; pouco tempo de descanso; tomar decisões de risco; suportar enorme pressão das competições; enorme responsabilidade social; avaliação permanente e crítica sob qualquer ângulo e a responsabilidade de muitos papéis assumidos dentro de uma equipe. Os autores verificaram que os treinadores trabalham arduamente na elaboração e execução dos processos de treinamento e precisam lidar com as diferenças individuais de seus esportistas, dos membros da comissão técnica e dos diretores esportivos (Brandão; Agresta \& Rebustini, 2002; Buceta, 2009).

Outra característica importante que o treinador, como líder precisa demonstrar é citada por Cruz e Gomes (1996):

[...] "Treinar implica, antes de tudo saber e ser capaz de comunicar e de se relacionar interpessoalmente com outras pessoas (atletas, dirigentes, jornalistas, adeptos, etc.). Por isso, à semelhança do que se passa com a formação de outros profissionais (ex. professores, médicos, psicólogos, etc.), os treinadores deverão ser especificamente 'treinados' na difícil 'arte' de comunicar" (Cruz \& Gomes, 1996, p. 403)

Alguns autores (Brandão \& Valdés, 2005) complementam, afirmando que treinar esportistas requer um planejamento meticuloso, criativo, reflexivo, com uma filosofia sólida, amor pelo esporte e ser capaz de conhecer as diferentes características psicológicas e comportamentais dos membros do 
grupo. Em suma, o treinador é o ponto de equilíbrio entre dois tipos de unidades, a organização ou clube a qual deve cumprir as suas exigências em termos de produção e rendimento e, os atletas, os quais precisa influenciar e motivar, assegurando-se de que as suas necessidades e aspirações são atingidas e de que estão satisfeitos com a sua participação na equipe ou organização (Cruz \& Gomes, 1996). Deste ponto de vista, fica claro, que é preciso que o treinador ou líder seja sensível, não só às exigências da tarefa, mas também às pessoas envolvidas.

A relação técnico-atleta é fundamental para o entendimento esportivo, uma vez que, normalmente, o treinador é o responsável pela preparação física, técnica, tática e até, psicológica de seus atletas. Pelo fato do treinador ser um líder e orientador é importante quer seja aceito por todos os membros do grupo. As relações interpessoais entre o técnico-líder e seus atletas tendem a desempenhar um papel importante na influência sob a motivação dos membros da equipe e na capacidade de trabalharem juntos em busca de objetivos comuns. A equipe esportiva é um meio coletivo complexo e heterogêneo, e por isso os problemas estratégicos devem ser resolvidos. Para tanto se faz necessário que o perfil comportamental do técnico como líder seja de fácil adaptação aos interesses da equipe e ao seu posicionamento filosófico. O técnico seja ele jovem ou veterano precisa observar uma série de normas bem definidas (Simões, 1994; Simões, Villaça, \& Gagliardi, 1993).
Sobre o exposto anteriormente, observa-se que tanto os atletas como o técnico necessitam aprender a conhecer-se, já que a cooperação entre ambos constituirá a base psicológica da individualização do treino. Cabe ao treinador dar início aos processos de heteroconhecimento e autoconhecimento, devido às funções no processo e à suposta maior maturidade, experiência e formação que possui (Serpa, 1996, 1997).

Pesquisadores da Psicologia do Esporte (Brandão \& Valdés, 2005; Chelladurai, 1993; Chelladurai et al., 1989; Simões, 1994) resumem as qualidades que um líder deve demonstrar para que sua relação com os atletas seja harmônica. Os autores afirmam que o papel do técnico é o de catalisador de sentimentos, por isso, ele deve ter duas virtudes: (1) ser alguém que entenda habitualmente de desempenhos físicos e que consiga discriminar, minuciosamente, o melhor desempenho de cada um em cada situação, posição e forma; (2) o técnico deve ser um pouco psicólogo, ou seja, deve entender os tipos emocionais específicos que compõem a equipe, aproveitando essa tipologia emocional para poder desenvolver as formas e táticas mais apuradas que compõem a estrutura dinâmica do desporto.

Relacionado com o comportamento dos técnicos, está o estilo de liderança que adotam (Brandão \& Valdés, 2005; Buceta, 2009; Chelladurai et al., 1989). O estilo de liderança do treinador, em geral, pode ser autocrático (o treinador toma decisões sem consultar os membros da equipe), participativo (permite 
que os membros da equipe participem de suas decisões), delegatório (o treinador delega a responsabilidade pela decisão aos membros da equipe) e, consultivo (o treinador consulta todos ou alguns membros da equipe embora reserve para si a decisão final). Em verdade, na prática cotidiana, os treinadores para ter êxito em sua liderança devem estabelecer um contínuo entre a opção mais democrática até a mais participativa (Buceta, 2009).

[...] "Estilos de liderança podem ser mudados. Técnicos e outros líderes podem alterar seus estilos e comportamentos para adaptar-se às demandas de uma situação" (Weinberg \& Gould, 2001, p. 215).

O líder pode ser intitulado como um profissional autoritário, democrático ou omisso, e seja qual for sua denominação, ainda assim, sua tarefa é árdua, pois ele precisa estar sempre em busca de alternativas e motivação, a fim de se manter em um determinado patamar (Simões, 1994). Este fato envolve o técnico esportivo como homem chave na orientação e liderança da equipe e a efetividade do estilo de liderança de um indivíduo é derivada de sua adaptação às situações (Weinberg \& Gould, 2001).

Estudos realizados por pesquisadores da The Ohio State University, nos Estados Unidos da América, sobre o comportamento do líder bem sucedido perante seu comportamento, apontam que os líderes mais eficientes são aqueles que propiciam a manutenção e realização dos objetivos comuns de sua equipe de trabalho em duas dimensões comportamentais de liderança: execu- ção de tarefas e relações sociais (Simões, 1994; Simões et al., 1993).

Existe um consenso entre os pesquisadores (Brandão \& Valdés, 2005; Lopes et al., 2004; Weinberg \& Gould, 2001), de que determinadas características dos atletas, como sexo, maturidade, idade, tempo de experiência no esporte, nível de capacidade e, tipo de temperamento e personalidade são essenciais para determinar o comportamento e a efetividade de um líder, conforme discutido anteriormente no Modelo Multidimensional de Liderança no Esporte (ver figura 1).

Além dessas variáveis, é essencial que o treinador tenha a sensibilidade para perceber a influência de fatores ambientais e situacionais e as características do esporte, ou seja, se é individual ou coletivo, o tamanho da equipe, as dimensões da comissão técnica, a tradição de sua equipe, o número de vitórias e fracassos e a quantidade de títulos conquistados (Buceta, 2009).

Sabendo-se que o tipo de liderança que $o$ treinador exerce influencia $o$ comportamento dos jogadores em jogos o objetivo desse estudo foi avaliar a percepção que os atletas de voleibol têm do comportamento preferido de liderança do treinador e sua influência em sua atuação nos jogos.

\section{MÉTODO}

\section{Amostra}

A amostra deste estudo foi constituída por 12 atletas de uma equipe masculina de voleibol de alto rendimento brasileira, categoria adulta, com média de idade de 24.6 anos \pm 4.8 anos e tempo de prática de $10.5 \pm 2.2$ anos. 


\section{Procedimentos}

Foi utilizado um questionário composto por uma única questão geradora que permitiu respostas abertas: "Você vê relação entre o estilo de liderança de seu treinador e a sua atuação em jogo? Comente sua resposta".

Os participantes foram informados do objetivo e procedimentos do estudo. Os questionários foram aplicados em conjunto, sem a presença do treinador e fora do horário dos treinos e jogos. $\mathrm{O}$ tempo médio de duração foi de 10 minutos. O presente estudo foi aprovado pelo Comitê de Ética em Pesquisa da Universidade São Judas Tadeu, São Paulo, Brasil, sob protocolo número 078/2005.

\section{Análise estatística}

Os atletas responderam por escrito a pergunta geradora. Os resultados foram analisados seguindo-se o Modelo do Discurso do Sujeito Coletivo (DSC) de Lefèvre e Cavalcanti Lefèvre (2003) com os seguintes passos: a) Identificação das ideias centrais (IC), a partir das expressões-chave, nesse caso, frases que tivessem relação com os objetivos do estudo; b) Identificação e agrupamento das ideias centrais e das ancoragens de mesmo sentido ou de sentido equivalente, ou de sentido complementar em categorias; c) Criação de uma ideia central ou ancoragem-síntese para cada um dos grupamentos que expressasse, da melhor maneira possível, todas as ideias centrais e ancoragens de mesmo sentido; d) Construção do DSC para cada grupamento identificado no passo anterior.

\section{RESULTADOS}

Os dados discursivos fornecidos pelos sujeitos foram analisados através do software QualiQuantiSoft (Lefèvre \& Cavalcanti Lefèvre, 2003). A seguir, no quadro 1, são apresentados em forma de expressões chave e idéias centrais os trechos selecionados nos diferentes discursos emitidos na questão norteadora: "Você vê relação entre o estilo de liderança de seu treinador e a sua atuação em jogo? Comente sua resposta".

Posteriormente, os discursos foram categorizados segundo similaridades ou equivalências de ideias tais como descritos a seguir: Categoria A - Influência Direta: discursos que se referem ao comportamento do treinador como tendo uma influência direta em sua atuação nos jogos (ver quadro 2); Categoria B - Não influência - discursos que se referem a uma não influencia do comportamento do treinador em sua atuação nos jogos (ver quadro 3); Categoria C - Influência Subordinada - discursos que se referem ao comportamento do treinador e sua influência em sua atuação nos jogos dependendo das circunstancias (ver quadro 4). O quadro 5 sintetiza em termos de frequência e porcentagem de respostas para cada categoria. 
Quadro 1

Expressões chave e as respectivas ideias centrais e ancoragens dos discursos emitidos na questão norteadora

\begin{tabular}{lc}
\hline \multicolumn{1}{c}{ Expressões Chave } & Ideias Centrais \\
\hline $\begin{array}{c}\text { S1 - Sim, acho que o técnico que nos passa } \\
\text { mais confiança faz melhorar o desempe- } \\
\text { nho. }\end{array}$ & $\begin{array}{c}\text { Sim. O técnico que nos passa mais confiança } \\
\text { faz melhorar o desempenho. }\end{array}$ \\
$\begin{array}{c}\text { S2 - Às vezes sim, às vezes não... Depende do } \\
\text { momento, do jogo, da situação. }\end{array}$ & Às vezes. \\
$\begin{array}{l}\text { S3 - Sim. A liderança do técnico é essencial } \\
\text { na minha atuação. }\end{array}$ & $\begin{array}{c}\text { Sim. A liderança do técnico é essencial na } \\
\text { minha atuação. }\end{array}$ \\
$\begin{array}{l}\text { S4 - Não. Para mim liderança e atuação são } \\
\text { coisas distintas. Se você é uma pessoa de }\end{array}$ & $\begin{array}{c}\text { Não. Liderança e atuação são coisas distin- } \\
\text { tas. }\end{array}$
\end{tabular}
"personalidade forte", ou seja, não influenciado pelos outros, a liderança de um terceiro, não impedirá a sua atuação em uma partida.

S5 - Sim, vejo... mas não é uma relação positiva.

S6 - Não. Eu acho que em quadra eu sou mais tranquilo, diferente do meu técnico... e muitas vezes mais sóbrio que ele...

S7 - Eu acho que o estilo do meu treinador é diferente de todos os outros... ele quer falar o tempo todo no ouvido do jogador e ao mesmo tempo insulta com palavras que põe o jogador pra baixo. Isso atrapalha bastante a cada jogador. Ele não é tranqüilo, é muito nervoso... Isso prejudica o grupo sempre.

S8 - Claro, acho o treinador, o espelho da equipe.

S9 - Sim! Acredito que poderia render muito mais a equipe, ajudando assim a vitória, se "ele" fosse um pouco mais otimista e companheiro nas horas difíceis do treino e principalmente nos jogos!

S10 - Sim. Acredito que nossa equipe é desorganizada e muito afoita em certos momentos; também acho que na maioria das partidas jogamos muito tensos. Para mim, um time tem sempre a cara do técnico e o nosso não é diferente.

S11 - Lógico! O técnico sempre é a nossa referência... então ele pode influenciar nosso desempenho tanto positivamente como negativamente.

S12 - Sim. A forma como um técnico passa uma informação técnica ou tática influencia sim no meu desempenho nos jogos.

Sim. Não é uma relação positiva.

Não. Em quadra eu sou mais tranquilo.

O estilo do meu treinador é diferente de todos os outros. Ele é muito nervoso e isso prejudica o grupo sempre.

Sim. O treinador é o espelho da equipe.

Sim. A equipe poderia render mais se ele fosse um pouco mais otimista e companheiro nas horas difíceis.

Sim. Nossa equipe é desorganizada e muito afoita em certos momentos. Um time tem sempre a cara do técnico e o nosso não é diferente.

Sim. Ele pode influenciar nosso desempenho tanto positivamente como negativamente.

Sim. A forma como um técnico passa uma informação influencia meu desempenho. 
Quadro 2

Expressões chave e ideias centrais das respostas de influência direta

\begin{tabular}{cc}
\hline \multicolumn{1}{c}{ Expressões Chave } & Ideias Centrais \\
\hline $\begin{array}{l}\text { S1 - Sim, acho que o técnico que nos passa } \\
\text { mais confiança faz melhorar o desempe- } \\
\text { nho. }\end{array}$ & $\begin{array}{c}\text { Sim. O técnico que nos passa mais confiança } \\
\text { faz melhorar o desempenho. }\end{array}$ \\
$\begin{array}{l}\text { S3 - Sim. A liderança do técnico é essencial } \\
\text { na minha atuação. }\end{array}$ & $\begin{array}{c}\text { Sim. A liderança do técnico é essencial na } \\
\text { minha atuação. }\end{array}$
\end{tabular}

S5 - Sim, vejo... mas não é uma relação positiva.

Sim. Não é uma relação positiva.

7 - Eu acho que o estilo do meu treinador é diferente de todos os outros... ele quer falar o tempo todo no ouvido do jogador e ao mesmo tempo insulta com palavras que põe o jogador pra baixo. Isso atrapalha bastante a cada jogador. Ele não é tranqüilo, é muito nervoso... Isso prejudica o grupo sempre.

S8 - Claro, acho o treinador, o espelho da equipe.

Sim. O treinador é o espelho da equipe.

S9 - Sim! Acredito que poderia render muito mais a equipe, ajudando assim a vitória, se "ele" fosse um pouco mais otimista e companheiro nas horas difíceis do treino e principalmente nos jogos!

S10 - Sim. Acredito que nossa equipe é desorganizada e muito afoita em certos momentos; também acho que na maioria das partidas jogamos muito tensos. Para mim, um time tem sempre a cara do técnico e o nosso não é diferente.

S11 - Lógico! O técnico sempre é a nossa referência... então ele pode influenciar nosso desempenho tanto positivamente como negativamente.

S12 - Sim. A forma como um técnico passa uma informação técnica ou tática influencia sim no meu desempenho nos jogos.

O estilo do meu treinador é diferente de todos os outros. Ele é muito nervoso e isso prejudica o grupo sempre.

Sim. A equipe poderia render mais se ele fosse um pouco mais otimista e companheiro nas horas difíceis.

Sim. Nossa equipe é desorganizada e muito afoita em certos momentos. Um time tem sempre a cara do técnico e o nosso não é diferente.

Sim. Ele pode influenciar nosso desempenho tanto positivamente como negativamente.

Sim. A forma como um técnico passa uma informação influencia meu desempenho.

A seguir, aparecem os Discursos do Sujeito Coletivo para cada categoria.

\section{DSC da Categoria A (Influência}

\section{Direta):}

Sim. O treinador é o espelho de uma equipe. A liderança do técnico é essencial na minha atuação, tanto positivamente, quanto negativamente (...) o técnico que nos passa mais confiança, faz melhorar o desempenho (...) Um time tem sempre a cara do técnico e o nosso não é diferente. O estilo do meu treinador é diferente de todos os outros. Ele é muito nervoso e isso prejudica o grupo sempre 
(...). Não é uma relação positiva. Nossa equipe é desorganizada e muito afoita em certos momentos... A equipe poderia render mais se ele fosse um pouco mais otimista $e$ companheiro nas horas difíceis.

\section{DSC da Categoria B (Não Influência):}

Não. Para mim liderança e atuação são coisas distintas. Se você é uma pessoa de "personalidade forte", ou seja, não influenciado pelos outros, a liderança de um terceiro, não impedirá a sua atuação em uma partida (...) Eu acho que em quadra eu sou mais tranquilo, diferente do meu técnico... e muitas vezes mais sóbrio que ele...

\section{DSC da Categoria C (Influência}

\section{Subordinada):}

Às vezes sim, às vezes não... Depende do momento, do jogo, da situação... [Obs. dos autores: $O$ discurso anterior se refere exclusivamente ao sujeito 2 , pois somente ele fez referência a essa categoria, não caracterizando, portanto um discurso coletivo.]

Quadro 3

Expressões chave e ideias centrais das respostas de não influência

\begin{tabular}{|c|c|}
\hline Expressões Chave & Ideias Centrais \\
\hline $\begin{array}{l}\text { S4 - Não. Para mim liderança e atuação são } \\
\text { coisas distintas. Se você é uma pessoa de } \\
\text { "personalidade forte", ou seja, não } \\
\text { influenciado pelos outros, a liderança de } \\
\text { um terceiro, não impedirá a sua atuação } \\
\text { em uma partida. }\end{array}$ & $\begin{array}{l}\text { Não. Liderança e atuação são coisas distin- } \\
\text { tas. }\end{array}$ \\
\hline $\begin{array}{l}\text { S6 - Não. Eu acho que em quadra eu sou } \\
\text { mais tranquilo, diferente do meu técnico... } \\
\text { e muitas vezes mais sóbrio que ele... }\end{array}$ & Não. Em quadra eu sou mais tranquilo. \\
\hline
\end{tabular}

Quadro 4

Expressões chave e ideias centrais das respostas de influência subordinada

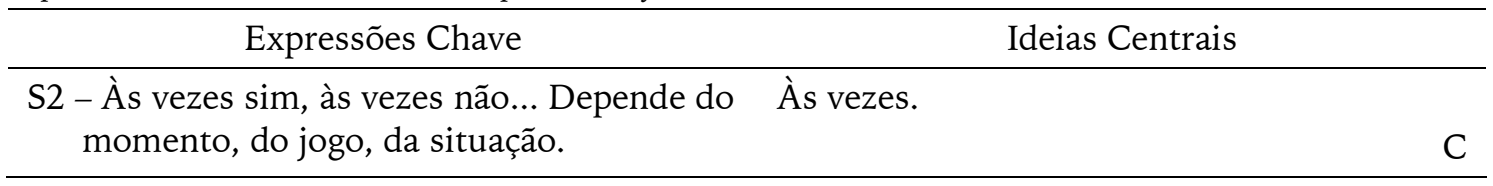

Quadro 5

Frequência e porcentagem de respostas em cada categoria

\begin{tabular}{ccc}
\hline Variáveis & $n$ & $\%$ \\
\hline A. Influência Direta & 9 & 75.0 \\
B. Não Influência & 2 & 16.7 \\
C. Influência Subordinada & 1 & 8.3 \\
\hline
\end{tabular}




\section{DISCUSSÃO}

De acordo com os resultados do DSC da categoria A, pode-se verificar que o comportamento do treinador possui uma significativa influência na atuação dos atletas no jogo. Podemos observar que, na percepção dos jogadores, essa influência aparece, na maioria das vezes, de maneira negativa na atuação dos mesmos. Quando relatam: "Ele é muito nervoso e isso prejudica o grupo sempre..." ou "Não é uma relação positiva... A equipe poderia render mais se ele fosse um pouco mais otimista e companheiro nas horas difíceis". Indica que talvez o treinador esteja focado, na maioria das vezes, nos aspectos negativos, ou seja, nos erros dos jogadores que acontecem durante uma partida.

Sobre isso, destaca-se a importância do autocontrole do líder, de modo a não aumentar o stress dos praticantes. Existem alguns erros que são muito comuns na atuação do treinador e possuem um impacto emocional negativo nos atletas. São eles: - tendência para ativar constantemente os atletas antes das competições; - inadequação dos "feedbacks" fornecidos aos atletas, muitas vezes, centrado apenas nos aspectos negativos; - abandono dos atletas após um mal resultado (Serpa, 1996, 1997)

[...] Os treinadores com menor habilidade para manejar o grupo de atletas e colaboradores podem ter um estilo de liderança mais rígido, quase sempre pouco participativo... (Buceta, 2009, p.41).

Os discursos apresentados corroboram com as dimensões de comportamento realçadas por muitos pesquisa- dores (Buceta, 2009; Brandão \& Valdés, 2005; Chelladurai, 1993; Chelladurai et al., 1989; Chelladurai \& Saleh, 1980; Serpa, 1996), de que uma liderança eficaz depende também da relação social que o treinador estabelece com seus subordinados e isso está associado a duas dimensões, uma voltada para a execução de tarefas e outra para as relações humanas. A primeira define-se pelos padrões de organização, canais de comunicação e métodos de procedimento utilizados pelo treinador, enquanto a segunda se refere à amizade, confiança mútua, respeito humano nas relações entre líderes e liderados. $\mathrm{O}$ comportamento de liderança desejável ou eficaz se caracteriza por resultados elevados em ambas as dimensões.

Um treinador eficaz, ou seja, um líder de sucesso precisa dominar competências verbais e não-verbais de comunicação e relação interpessoal. Mais especificamente a necessidade de saber enviar mensagens aos outros, de possuir competências de atendimento; competências não-verbais e, competências de gestão de conflitos e confrontações (Cruz \& Gomes, 1996). Entretanto, a análise do processo de instrução nos momentos anteriores a competição não tem sido para Mesquita; Rosado; Januário \& Barroja (2008) adequadamente estudado, mesmo que treinadores e atletas considerem esses períodos particularmente importantes.

[...] Uma vez que os atletas usualmente experenciam altos niveis de ansiedade e nervosismo, possivelmente afetando sua capacidade de processar informações, o técnico precisa ter um cuidado extra quando fornecer informa- 
ção durante a competição. (Mesquita et al., 2008, p. 402).

Nesta perspectiva, geralmente, os atletas esperam ter um técnico competente tecnicamente e que não seja excessivamente científico, que seja companheiro e amigo, sem muita cordialidade, mas justo no seu relacionamento com os companheiros de equipe. Sobre os aspectos profissionais de um líder bem sucedido duas dimensões comportamentais são importantes: postura profissional e execução de tarefas. O fator postura profissional é definido como o "desempenho" do técnico ao executar as tarefas esperadas para a sua função. Já a dimensão execução de tarefas é definida como o comportamento de liderança do técnico ao comandar sua equipe, com a definição dos papéis dos diferentes membros, forma de comunicar-se com o grupo e métodos utilizados para cumprir o seu trabalho (Serpa, 1997; Simões, 1994).

Quanto ao DSC da categoria B, verificamos que o comportamento do treinador não possui uma significativa influência na atuação dos atletas em um jogo. Isso é notório quando relatam: "Não. Para mim liderança e atuação são coisas distintas..."

Esses resultados são interessantes porque, diferentemente dos outros atletas, apenas dois não perceberam nenhum tipo de influência em relação ao comportamento do treinador e sua atuação nos jogos, o que apresenta uma incoerência em grande parte dos estudos sobre as atitudes do treinador e o desempenho dos atletas (Bronfenbrenner, 1996; Buceta, 2009; Chelladurai, 1993; Cruz \& Gomes, 1996; Serpa, 1996).
No entanto o líder tem um poder quase mágico para modificar como se trata a uma pessoa, como se atua, o que se faz e inclusive o que se pensa e o que se sente (Buceta, 2009; Maxwell, 2007).

[...] O que leva as pessoas a desejarem seguir um líder? Por que se sujeitam relutantemente a um líder enquanto seguem outro com entusiasmo até os confins da terra? O que separa os teóricos em liderança dos líderes bem-sucedidos que comandam efetivamente no mundo real? A resposta reside nas qualidades de caráter de cada indivíduo. (Maxwell, 2007, p. 11).

Porém, para uma pessoa cumprir efetivamente seu papel é preciso conhecer as demandas deste papel e o stress e o apoio que a pessoa que o executa recebe de seu ambiente. O técnico, como um líder, influi diretamente no desempenho e na personalidade de seus jogadores. Por sua vez estes mesmos jogadores através da percepção que têm da capacidade profissional, técnica e psicossocial de seu técnico poderão facilitar ou impedir o comportamento individual do técnico (Brandão, 1996).

Ao analisar o DSC da categoria C, podemos constatar que os atletas percebem a diferença em sua atuação no jogo em relação ao comportamento do treinador apenas em alguns momentos, quando relatam: "Às vezes sim, às vezes não... Depende do momento, do jogo, da situação..."

Neste sentido, a influência do treinador em seus atletas será tanto maior quanto mais estes perceberem que ele compreende a vivência da situação competitiva, o que contribui, em gran- 
de medida, para a harmonia de pensamento e atitudes entre atletas e treinador, com significativo impacto (Serpa, 1996).

\section{CONCLUSÕES}

Através dos dados obtidos pelos DSCs pôde-se chegar as seguintes conclusões.

O comportamento do treinador tende a influenciar diretamente a atuação dos atletas durante os jogos. Essa influencia nem sempre se dá de forma positiva, o que significa que muitos resultados negativos da equipe dependem do comportamento do treinador.

O tom de voz que o treinador utiliza ao fornecer uma informação, a quantidade e a qualidade dos estímulos fornecidos por ele, o momento das intervenções e os momentos em que ele exerce um comportamento mais opressivo ou um comportamento voltado para instrução e reforço são cruciais para determinar se a influência na atuação das atletas será de conteúdo positivo ou negativo. Portanto, faz-se necessário que o treinador considere essas variáveis para adaptar seu comportamento de acordo com as diferentes situações impostas no jogo e com as características individuais dos atletas para que esses possam atingir seu máximo desempenho e se sintam satisfeitos. Neste contexto, o comportamento do técnico e sua capacidade de comunicação são fundamentais para uma liderança efetiva.

A questão norteadora permitiu aos sujeitos, discursar sobre o tema proposto e proporcionou oportunidades ao pesquisador para conhecer a fundo as vivências e as representações que os sujeitos da amostra têm sobre o comportamento do técnico e a sua relação com a atuação no jogo e, por fim, proporcionou maior força no rigor da validade dos dados coletados, já que pôde levar o pesquisador bem próximo da essência da questão em estudo.

\section{REFERÊNCIAS}

Brandão, M. R. F. (1996). Equipe nacional de voleibol masculino: Um perfil sóciopsicológico à luz da ecologia do desenvolvimento humano. Dissertação de mestrado não publicada, Universidade Federal de Santa Maria, Santa Maria, Rio Grande do Sul, Brasil.

Brandão, M. R. F. (2001). O papel do treinador como motivador do treinamento desportivo. In I. A. Dobransky \& A. A. Machado (Eds.), Delineamentos da psicologia do esporte: Evolução e aplicação (pp. 153-166). Campinas, Brasil: UNESP.

Brandão, M. R. F., Agresta, M., \& Rebustini, F. (2002). Estados emocionais de técnicos brasileiros de alto rendimento. Revista Brasileira de Ciência e Movimento, 10(3), 25-29.

Brandão, M. R. F., \& Valdés, H. (2005). La utilización de estratégias motivacionales por los entrenadores: Un aporte de la psicología del deporte. In M. Roffé \& F. G. Ucha (Eds.), Alto rendimiento, psicología y deporte: Tendencias actuales (pp. 115-130), Buenos Aires, Argentina: Lugar Editorial.

Bronfenbrenner, U. (1996). A ecologia do desenvolvimento humano: Experimentos naturais e planejados. Porto Alegre: Artes Médicas.

Buceta, J. M. (2009). Psicologia dos treinadores esportivos: Conceitos fundamentais e áreas de intervenção. 
In M. R. F. Brandão \& A. A. Machado (Eds.), Coletânea psicologia do esporte e do exercício: $O$ treinador e a psicologia do esporte, (Vol. 4, pp. 17-40). São Paulo, Brasil: Editora Atheneu.

Chelladurai, P. (1993). Leadership. In R. Singer, \& L. Tennant (Eds.), Handbook of research on sport psychology (pp. 647671). New York, EUA: Macmillan.

Chelladurai, P., Haggerty, T. R., \& Baxter, P. R. (1989). Decision style choices of university basketball coaches and players. Journal of Sport and Exercise Psychology, 11(2), 201-215.

Chelladurai, P., \& Saleh, S. (1980). Dimensions of behavior in sports: Development of leadership scale. Journal of Sport Psychology, 2(1), 34-45.

Costa, V. T. (2003). Analise do perfil de liderança atual e ideal de treinadores de futsal de alto rendimento, por meio da escala de liderança no desporto. Dissertação de Mestrado não publicada, Escola de Educação Física, Fisioterapia e Terapia Educacional, Universidade Federal de Minas Gerais, Belo Horizonte, Minas Gerais, Brasil.

Côté, J., Salmela, J., Trudel, P., Baria, A., \& Russell, S. (1995). The coaching model: A grounded assessment of expert gymnastic coaches' knowledge. Journal of Sport and Exercise Psychology, 17(1), 1-17.

Cruz, J. F. \& Gomes, A. R. (1996). Liderança de equipes desportivas e comportamentos do treinador. In J. Cruz (Ed.), Manual de Psicologia do Desporto (pp. 389-409). Lisboa, Portugal: Edições S.H.O.

Horn, T. S. (1992). Advances in sport psychology. Illinois, EUA: Human Kinetics.

Lefèvre, F. \& Cavalcanti Lefèvre, A.M. (2003). O discurso do sujeito coletivo. Caxias do Sul, Brasil: EDUCS.
Lopes, M., Samulski, D., \& Noce, F. (2004). Análise do perfil ideal do treinador de voleibol das seleções brasileiras juvenis. Revista Brasileira de Ciência e Movimento, 12(4), 51-55.

Maxwell, J. C. (2007). As 21 indispensáveis qualidades de um líder. Rio de Janeiro, Brasil: Thomas Nelson.

Mesquita, I., Rosado, I., Januário, N., \& Barroja, E. (2008). Athlete's retention of a coach's instruction before a judo competition. Journal of Sports Science and Medicine, 7, 402-407.

Serpa, S. (1996). A relação treinador-atleta. J. Cruz (Ed.), Manual de Psicologia do Desporto (pp. 411-423). Lisboa, Portugal: Edições S.H.O.

Serpa, S. (1997). Treinador e liderança no desporto. In F. Guillen (Ed.), La psicología del deporte en España al final del milenio. Las Palmas, Espanha: Universidad de Las Palmas de Gran Canaria.

Simões, A. C. (1994). Esporte: Análise do comportamento de liderança de técnicos de handebol. Revista Paulista de Educação Física, 8(1), 17-29.

Simões, A. C., Villaça, A. C., \& Gagliardi, J. (1993). Características pessoais atribuídas por atletas a técnico de equipe de alto rendimento. Revista Paulista de Educação Física, 7, 35-43.

Stogdill, R. (1974). Handbook of leadership. New York, EUA: Free Press.

Terry, P., \& Howe, B. (1984). Coaching preferences of athletes. Canadian Journal of Applied Sport Sciences, 9, 188193.

Weinberg, R. S., \& Gould, D. (2001). Fundamentos da psicologia do esporte e do exercício. Porto Alegre, Brasil: Artmed. 